Cuadernos de Filología Clásica. Estudios Latinos

ISSN: 1131-9062

https://dx.doi.org/10.5209/cfcl.64894

\title{
El epigrama 10.47 de Marcial (Vitam quae faciant beatiorem) en algunos poetas neolatinos $^{1}$
}

Manuel Mañas Núñez

Recibido: 28/05/2018 / Aceptado: 11/06/2019

Resumen. El presente artículo analiza una imitación cristiano-católica que Juan de Silva escribió de este epigrama latino a finales del siglo XVI en tercetos castellanos. También examinaremos unas cuantas recreaciones neolatinas que humanistas europeos, la mayoría de ellos alemanes de los círculos reformistas y protestantes, hicieron entre los siglos XVI y XVII, con una clara hostilidad, no tanto hacia Marcial, como principalmente contra Epicuro. Y concluiremos el trabajo con la labor editorial de Scriverio, un «Marcial redivivo», y el epigrama que su amigo Hugo Grocio escribió para ensalzar su edición de Marcial.

Palabras clave: Marcial; tradición clásica; epigrama neolatino.

\section{[en] Martial' epigram 10.47 (Vitam quae faciant beatiorem) in Some Neo- Latin Poets}

\begin{abstract}
This paper studies a Christian-catholic imitation of this Latin epigram that Juan de Silva wrote at the end of the 16th century in Castilian verses. Also we will examine several Neo-latin recreations that European humanists, mainly Germans of the circles Reformists and Protestants, did between the XVIth and XVIIth century, with a clear hostility, not so much towards Martial, since principally against Epicurus. The article finishes with the publishing labor of Scriverius, a «revived Martial», and the epigram that his friend Hugo Grotius wrote to exalt his Martial's edition.
\end{abstract}

Keywords: Martial; classic tradition; neo-Latin epigram.

Sumario. 1) El epigrama 10.47 de Marcial; 2) Marcial cristianizado; 2.1) Lectura católica; 2.2) Lectura reformista-protestante; 3) Marial redivivo; 4) Conclusiones.

Cómo citar: Mañas Núñez, M., «El epigrama 10.47 de Marcial (Vitam quae faciant beatiorem) en algunos poetas neolatinos», en Cuad. Filol. Clás. Estud. Lat. 39.1 (2019), 93-110

Decía don Miguel de Unamuno en su Diario íntimo (1897), refiriéndose al último endecasílabo del epigrama 10.47 de Marcial (13: summum nec metuas diem nec optes), que este verso le parecía «la crema de la sabiduría», pero no de la sabiduría cristiana, sino «de la sabiduría del demonio, pagana». Y el propio Unamuno, que traducía así esta máxima: «Al último día ni lo desees, ni lo temas», explicaba, siguiendo las Conferencias espirituales del P. Faber (1814-1863) (Zubizarreta 1960), que no

\footnotetext{
1 Este artículo se inscribe en la línea del Proyecto de Investigación FFI2017-82101-P, dirigido por el Dr. D. Luis Merino Jerez y subvencionado por el Ministerio de Economía, Industria y Competitividad.

$2 \quad$ Facultad de Filosofía y Letras. Universidad de Extremadura. mmanas@unex.es
} 
temer a la muerte era algo anticristiano, porque suponía «tratar con ligereza al que hizo de ella [de la muerte] un castigo», al tiempo que no desearla es tratar con indiferencia a Dios, a quien no podemos acceder sin antes dejar atrás esta vida terrena ${ }^{3}$. En consecuencia, don Miguel desdijo a Marcial e invirtió su sententia transformándola en otra más cristiana, menos epicúrea y más acorde con su sentimiento trágico de la vida: «Teme y desea tu último día» (Unamuno 2012, 91), precisamente lo contrario de lo que preceptuaba Epicuro en su Epístola a Meneceo, cuando criticaba a Teognis su idea de que lo mejor para el hombre era no haber nacido, pero que, una vez nacido, lo preferible era traspasar cuanto antes las puertas del Hades (Thgn.425, 427; Epicur., en D.L.10.126).

Estas reflexiones de Unamuno no hacen más que poner de manifiesto que el citado epigrama de Marcial es uno de los más famosos del autor y de los que mayor fortuna han tenido en la tradición clásica del Bilbilitano desde el Renacimiento hasta nuestros días (Sullivan 1991, 216), siendo versionado, imitado y emulado por numerosos poetas hispanos, desde Romero de Cepeda en el siglo XVI, pasando luego su recepción literaria por Lope de Vega, Manuel Salinas y Lizana, Juan de Jáuregui y el capitán Fernández de Andrada durante el Barroco y llegando incluso, según vemos, hasta autores del 98, como Unamuno, y a poetas contemporáneos como Jaime Gil de Biedma y Luis Alberto de Cuenca (Laguna 2000; 2017). Y es que Marcial, como hispano que era, fue siempre muy apreciado en España, aunque también fue objeto de rechazo fuera de nuestras fronteras precisamente por ser español (Gil 2004). También en la literatura inglesa y alemana ejerció notable influjo (Sullivan 1986; Damschen y Heil 2004, 187 y 380-6). Y en las letras francesas son preciosos los dos sonetos que el célebre impresor Cristophe Platin (1520-1589) escribió, ambos inspirados en el de Marcial, celebrando los placeres de este mundo, titulado uno Le bonheur de ce monde y el otro Sonnet de l'Épicurien, señalados y estudiados por Rodríguez Moñino (1932) y Laguna (2017).

Nosotros vamos a examinar en el presente estudio una imitación cristiano-católica que Juan de Silva escribió de este epigrama latino a finales del siglo XVI en tercetos castellanos. También presentaremos unas cuantas recreaciones neolatinas que humanistas europeos, la mayoría de ellos alemanes de los círculos reformistas y protestantes, hicieron entre los siglos XVI y XVII, con una clara hostilidad, no tanto hacia Marcial, como principalmente contra Epicuro. Habrá, pues, que ubicar estas piezas neolatinas dentro del Humanismo luterano que pretende una regeneración moral de la Iglesia y de la sociedad predicando su doctrina reformista con un claro ánimo antiepicúreo. Y concluiremos el trabajo con la labor editorial de Scriverio, un «Marcial redivivo», y el epigrama que su amigo Hugo Grocio escribió para ensalzar su edición de Marcial.

\section{El epigrama 10.47 de Marcial}

El epigrama 10.47 de Marcial tiene por destinatario a su amigo y protector Julio Lucio Marcial. Era este hombre una persona muy allegada al poeta y más de una vez le había prestado su ayuda (Leberl 2004, 138); por ello le dedica Marcial el libro VI,

Faber $(1860,132)$ : «Not to fear death is a slight to Him who made it our special punishment. Not to desire death is an indifference to Him, whom we can only reach by passing througt it». 
y quizás también el III, de su colección ${ }^{4}$. La composición, que supone un manifiesto vitalista de la visión particular que el poeta tiene sobre la felicidad de raíz epicúrea a la que parecen aspirar las clases medias romanas (Sullivan 1991, 216), va a aconsejar un disfrute moderado y epicúreo de la vida, basado no en el placer puramente hedonista de la misma, sino en la vida sencilla y retirada del sabio, disfrutando del contacto con la naturaleza y de las relaciones amistosas nacidas del otium productivo, evitando, en la medida de lo posible, el lujo, el lucro, el poder y las convenciones y obligaciones sociales. Es, entonces, una posición vitalista de la existencia humana, en la que se disfrute mesuradamente de la vida y no se tema ni se desee la muerte, muy en la línea del filósofo de Samos y del Carpe diem y Beatus ille horacianos, donde el suicidio estoico, predicado por Séneca como salida digna de las situaciones complicadas, ni siquiera se contempla. Este ideario entusiasta con la vida y con sus pequeños placeres lo había expuesto Marcial en otros epigramas (2.90 o 5.20), pero donde mejor plasma su modelo perfecto de vida es precisamente en este epigrama que nos ocupa. Aquí, en efecto, el Bilbilitano hace un elogio de la vida sencilla del campo y del retiro del sabio en la naturaleza y, en cierta manera, un denuesto de la vida ciudadana y política tan llena de convenciones y ataduras sociales (Watson 2003, 139-140), muy en sintonía con lo que luego se llamaría «Desprecio de corte y alabanza de aldea». Veamos el texto de Marcial por la edición de Lindsay (1987):

\begin{tabular}{|c|c|}
\hline $\begin{array}{l}\text { Vitam quae faciant beatiorem, } \\
\text { iucundissime Martialis, haec sunt: } \\
\text { res non parta labore sed relicta; } \\
\text { non ingratus ager, focus perennis; } \\
\text { lis numquam, toga rara, mens quieta; } 5 \\
\text { vires ingenuae, salubre corpus; } \\
\text { prudens simplicitas, pares amici; } \\
\text { convictus facilis, sine arte mensa; } \\
\text { nox non ebria sed soluta curis; } \\
\text { non tristis torus et tamen pudicus; } 10 \\
\text { somnus qui faciat breves tenebras; } \\
\text { quod sis esse velis nihilque malis; } \\
\text { summum nec metuas diem nec optes. }\end{array}$ & $\begin{array}{l}\text { Los placeres que pueden hacer la vida más feliz, } \\
\text { mi muy entrañable Marcial, son los siguientes: } \\
\text { patrimonio no ganado con sudor, sino heredado; } \\
\text { campos de cultivo agradecidos, hogar con fuego } \\
\text { constante; } \\
\text { pleitos nunca, toga rara vez, mente tranquila; } \\
\text { fuerzas dignas de hombre libre, cuerpo saludable; } \\
\text { inteligente sencillez, amigos iguales; } \\
\text { banquetes frugales, mesa sin lujo; } \\
\text { noche sin borracheras, pero libre de preocupaciones; } \\
\text { no triste lecho y, sin embargo, casto; } \\
\text { un sueño que acorte las tinieblas de la noche; } \\
\text { lo que seas, querer serlo y no preferir nada más; } \\
\text { no temer el día final ni tampoco desearlo. }\end{array}$ \\
\hline
\end{tabular}

El éxito de este epigrama hay que cifrarlo en diversas circunstancias. Primeramente, atendiendo a la forma, hay que señalar la aparente facilidad del poema, con la parataxis y la oración nominal como elementos estilísticos dominantes, lo que hace que su lectura, traducción y comprensión resulten exteriormente sencillas. En segundo lugar, la estructura de la composición tampoco reviste especial dificultad, pues normalmente se distingue una primera parte (vv. 1-2) destinada a exponer el planteamiento o el título del poema y el nombre del destinatario: «Los placeres que pueden hacer la vida más feliz», y una segunda parte (vv. 3-13) en la que se enumeran uno a uno los requisitos necesarios para alcanzar la felicidad suma en esta vida. Asimismo, otro factor capital que ha dado fama a este epigrama es su contenido doctrinal de tono epicúreo, bien por influencia directa del filósofo griego o por el tratamiento horaciano del tema. El caso 
es que muchas de las ideas éticas contenidas en estos versos responden al ideal de vida feliz que profesa el sabio estoico-epicúreo: la felicidad como meta de la filosofía; la interacción entre cuerpo sano (aponía) y espíritu tranquilo (ataraxía); el rechazo a las preocupaciones derivadas de la actividad política, de los afanes mercantiles, de las supersticiones religiosas o del temor a la muerte; la exaltación de la amistad como el mayor de los bienes; y la elevación de la autárkeia o autosuficiencia y de la frugalidad como principios fundamentales de una vida autosuficiente, que no conformista, y sencilla que nos guíe hasta la ausencia de dolor en el cuerpo y de turbación en el alma (Laguna 2000, 323-327). Pero todo este ideario epicúreo está matizado por cierto aristotelismo bebido de Horacio, apreciable en esa sensación de mesura, justa proporción y dorada medianía (aurea mediocritas, Hor.Carm.2.10.5) que se respira en el epigrama y que no deja de ser el sentimiento de un poeta maduro que aún cree posible encontrar la felicidad en lo que le resta de vida terrena (Encuentra 2015, 57). Por último, si el presente poema ha tenido tan larga tradición literaria, ha sido porque los preceptos éticos en él expuestos concuerdan muy bien con el neoestoicismo cristiano que, mezclado con el neoepicureísmo renacentista, domina en los Siglos de Oro españoles y en el espíritu humanístico europeo de los siglos XVI y XVII. De hecho, ya en los primeros siglos del cristianismo fueron estos endecasílabos de Marcial inspiradores de orationes en las que Ausonio y Paulino asumen el enfoque protréptico de estos planteamientos y los transforman en plegarias cristianas de la literatura latina (Encuentra 2015).

Y es que, rememorando quizás el comienzo de la Epístola a Meneceo de Epicuro (D.L.10.122), Marcial, aun estando ya en las puertas de la vejez, no se siente todavía cansado de filosofar, esto es, de buscar la felicidad. El Bilbilitano, en efecto, en lo que parece una reflexión de senectud, se replantea el sentido de su vida tras el derrocamiento de Domiciano en el año 96 y expone a su amigo y protector, Julio Marcial, todo un ideario ético que más parece un diálogo interior y una proposición de intenciones futuras que el propio Marcial se marca para sí mismo que una retahíla de consejos destinados a su amigo. Marcial, entonces, siendo fiel a los dogmas propuestos en su epigrama, busca la auténtica felicidad, no ya en Roma, sino en el retiro de su finca de Nomento, invitando a comer a sus mejores amigos y deleitándolos, no con manjares exóticos y exuberantes, sino con sencillas exquisiteces cultivadas en esas mismas tierras que no ha ganado con el sudor de su frente, sino que le han sido regaladas (Mart. 10.48). Y, para alcanzar esa felicidad que ya no pueden ofrecerle las preocupaciones, agobios, delaciones e intrigas que se viven en Roma, decide intentar ser feliz, esto es, alcanzar la aponía y la ataraxia; se propone, así, llevar la vida retirada del sabio epicúreo y profesar su ideal de autarquía, no ya en la capital del Imperio, sino regresando a su patria y asentándose en su añorada Bílbilis natal (Encuentra 2015, 57), a la espera tranquila y serenamente, sin temerlo ni desearlo, del summum diem, ya sentido como culminación de una vida plena y feliz.

\section{Marcial cristianizado}

El neoepicureísmo, iniciado en el Renacimiento por Cosma Raimondi, supuso la aceptación de algunas tesis epicúreas leídas en clave místico-cristianas (Mañas 1997), luego asumidas por autores neoestoicos salidos de la officina de Justo Lipsio, tales como El Brocense, su discípulo Correas o Quevedo. Así, para Sánchez de las 
Brozas, la doctrina de Epicuro fue mejor que la peripatética y que la estoica y Epicuro un buen hombre y, por así decir, un buen cristiano:

La primera i la mejor de todas..., si bien se entendiera. I fue que puso la felicidad i bienaventuranza in voluptate, en el deleite i contento... que este deleite i gozo se entiende del ánimo... así que el deleite del ánimo es el que da la bienaventuranza. Esta opinión de Epicuro vino a ser tan abominable, por ser mal entendida de sus sequaces i tomada corporalmente i en afrenta de su inventor, porque él fue mui abstinente i mui buen ombre (Sánchez de las Brozas 1612, 6r-v).

En el mismo tono se expresó también Quevedo en su Defensa de Epicuro contra la común opinión de 1635 , quien no duda en distorsionar la doctrina epicúrea para vincularla con la estoica y con Séneca y, en consecuencia, con el cristianismo, entendiendo que

Epicuro puso la felicidad en el deleite, y el deleite en la virtud, doctrina tan estoica, que el carecer de este nombre no la desconoce (Quevedo 1635, 5).

Y también Gonzalo Correas quiso hermanar, siguiendo a su maestro El Brocense, a Epicuro y a Epicteto, proclamándolos como auténticos cristianos, en su traducción de la Tabla de Kebes, en cuya nota 5 leemos:

Epikuros [son] los ke sigieron a Epikuro, ke puso la felicidad en el deleite i, entendiéndolo él del ánimo, se lo interpretó el vulgo por el deleite korporal. En el Griego está Hedonikoi, ke es lo mesmo que deliziosos o deleitables, los ke tratan de la dulzura, deleite i suavidad de bivir. En Romanze ia Epikuro es rezibido por glotón i komedor (Korrea 1630, 115).

Asimismo, este epigrama epicúreo de Marcial que estamos estudiando podía también cristianizarse con tan solo introducir en él alguna referencia explícita a Dios, como si la doctrina filosófica pragmática en él plasmada derivara directamente de las fuentes bíblicas y evangélicas: epicureísmo convertido en neoepicureísmo. Y ello podía hacerse desde un doble punto de vista: realizando del epigrama una lectura católica o interpretándolo en tono reformista-protestante. Lo primero lo hizo, por ejemplo, Juan de Silva; lo segundo, Lutero y otros poetas de su mismo círculo.

\subsection{Lectura católica}

Efectivamente, don Juan de Silva, Conde de Portalegre, a finales del siglo XVI, hastiado ya en su vejez de la vida cortesana (Bouza 1994), realizó una imitatio del epigrama de Marcial, recogiendo casi todos los preceptos estoicos-epicúreos expresados allí, pero introduciendo al principio y al final un par de alusiones a Dios, como si los dogmas poetizados en tercetos proviniesen, no de Marcial o de Epicuro, sino de los textos sagrados o de algún catecismo cristiano y católico. Juan de Silva, por tanto, acepta las ideas contenidas en el epigrama del poeta latino y las considera ortodoxas y concordantes con la sana fe católica de la España de Felipe II: 
Las cosas que nos pueden dar la vida, en este mundo, alegre y descansada, yo las diré; quien quiera a Dios las pida.

Moderada hacienda, no ganada con trabaxo ni cargos de conciencia, 5 mas de padres o abuelos heredada. Heredades que acudan sin falencia, con pan, vino, fruta, y tanta leña que tenga siempre el fuego suficiencia. No triste, mas graciosa y casta dueña, 10 vino que no embriague, mas contente, y sueño que la noche haga pequeña. Pleitos ningunos, ánimo inocente, hidalgas fuerzas, cuerpo entero y sano, poca mas bien tratada y buena gente. 15 Mesa sin arte, el comer temprano, el vestir floxo, iguales amistades, y saber conservar el trato humano. No buscar grandes cortes ni ciudades, donde se vive con engaño y arte, 20 y son mui ordinarias las maldades, mas pueblo chico y puesto en buena parte, de fértil suelo y cielo bien templado de gente conversable y que no harte.

Estar contento siempre con su estado, 25

dignidad popular no procurarla, servir a Dios alegre y descansado, la muerte, ni temella ni buscalla ${ }^{5}$.

Francisco del Rosal (ca. 1560-1610), médico cordobés formado en la Universidad de Salamanca, que cultivó, al igual que el también médico extremeño Sorapán de Rieros (1572-1638), la literatura paremiológica, cita el epigrama de Marcial y la versión realizada por Juan de Silva para explicar el refrán «Mi casa y mi hogar, cien sueldos val», detectando perfectamente que el contenido del poema es una laudatio de la vida tranquila y en familia:

Muchos alabaron la vida quieta y doméstica, y entre ellos Marcial en un docto Epigramma, que por estar traducido por un hombre docto de estos Reynos, lo pondré aquí con su traducción (Del Rosal 1975, 68).

Las correspondencias con Marcial son bastante claras, si bien apreciamos que Juan de Silva acude sistemáticamente a la amplificatio y a veces un simple verso del original ha dado lugar en la imitación a un terceto entero, siendo en este sentido el sintagma latino toga rara (5b) el que mayor desarrollo ha tenido en la versión de

5 Se encuentra en la Biblioteca Nacional de Madrid, Ms. 8894, fols. 154r-v. Fue también recogida por Menéndez Pelayo (1951, VII 133-134). 
Juan de Silva, sin duda porque el poeta español pretende poner el énfasis en el mencionado tópico del menosprecio de la corte que perturba los sentidos y la alabanza de la vida sencilla y apacible de la aldea. Un listado de correspondencias podría ser éste:

\begin{tabular}{|c|c|}
\hline Marcial, versos & Juan de Silva, versos \\
\hline $1-2$ & $1-3$ \\
\hline 3 & $4-6$ \\
\hline 4 & $7-9$ \\
\hline $5 \mathrm{a}$ & $13 \mathrm{a}$ \\
\hline $5 \mathrm{~b}$ & $19-24,26$ \\
\hline $5 \mathrm{c}$ & $13 \mathrm{~b}$ \\
\hline 6 & 14 \\
\hline $7 \mathrm{a}$ & 15 \\
\hline $7 \mathrm{~b}$ & $17 \mathrm{~b}$ \\
\hline 8 & $16-17 \mathrm{a}$ \\
\hline $9-11$ & $10-13$ \\
\hline 12 & 25 \\
\hline 13 & 28 \\
\hline
\end{tabular}

Juan de Silva, efectivamente, abre y cierra su imitatio apelando a Dios, con lo que pasa directamente a cristianizar el epigrama del Bilbilitano, aconsejando al lector que, si quiere ser un buen cristiano, debe rezar a Dios, encomendarse a él y pedirle todo este listado de requisitos o condiciones que nos harán la vida «más alegre y descansada» (1-3); pero también debe el lector, para conseguir todo esto, «servir a Dios alegre y descansado» (27). Lo demás, es una versio amplificada del original latino, con numerosos rellenos que tienen por finalidad colmar el cómputo silábico y conformar tercetos encadenados. Así, la res non parta labore, sed relicta (3) de Marcial queda amplificada con añadidos como «moderada» hacienda que no se ha ganado «ni con cargos de conciencia» sino que se ha heredado «de padres y abuelos» (4-6). El verso 4: Non ingratus ager, focus perennis, ha quedado transformado y completado con elementos nuevos, de forma que sean unas heredades que den sin engaño «pan, vino y fruta y tanta leña» (8) que mantengan siempre el fuego encendido. Y éste, en general, es el proceder versificador de Juan de Silva, aunque, como ya se ha dicho, la mayor amplificatio la leemos en las estrofas VII y VIII, donde desarrolla en seis versos el tópico del «Desprecio de corte y alabanza de aldea», que sólo estaba apuntado en Marcial, y recomienda al lector, por propia experiencia, que evite la vida en las metrópolis y sus grandes cortes, pues están llenas de gentes malvadas e intrigantes, y escoja para llevar una vida serena y tranquila una pequeña aldea, donde habitarán gentes buenas y hospitalarias, que parece ser el asunto que más preocupa a Juan de Silva, pues ya antes había advertido que su aprecio iba dirigido a la «poca mas bien tratada y buena gente» (15) y hacia la cualidad de «saber conservar el trato humano» (18).

\subsection{Lectura reformista-protestante}

Pero no siempre Epicuro tuvo esta sana aceptación en el Humanismo renacentista. Sabido es que Martín Lutero no podía admitir la negación de la inmortalidad del alma y de la providencia divina sostenida por Epicuro y que, por tanto, el filósofo griego representaba para él lo peor del paganismo y de la corrupción moral, por lo que no dudó en enfrentarse a los dogmas epicúreos en sus obras y en aplicar el 
calificativo de «epicúreo», como sinónimo de «demonio corrupto», tanto al papa y a su corte como a los teólogos de Lovaina y a Erasmo (Paladini 2011, 41-58). Y, en general, dentro de la corriente cristiana reformista, liderada por Lutero, pero también seguida por Stingel, Siber o Reusner, Epicuro es vilipendiado como anticristiano y como padre espiritual de los católicos corruptos, viéndose también salpicado en esta controversia antiepicúrea el epigrama de Marcial que estamos estudiando y convirtiéndose éste en un carmen maldito. La respuesta, en efecto, de los reformadores es la imitación del epigrama 10.47 de Marcial, pero transformándolo, mediante la aemulatio, en un poema no sólo cristiano, sino también totalmente reformista, denominado ahora carmen antimartiale. Lutero, en efecto, al igual que otros reformadores, recomendó que poetas como Catulo y Marcial, con materiales altamente eróticos, sexuales y escatológicos, fueran excluidos de la enseñanza escolar, aunque su familiaridad con los versos del Bilbilitano era grande, como se comprueba en la aemulatio que escribió del epigrama 10.47 al hilo de la enarratio al Salmo 128, que fue objeto de una traducción amplificada en endecasílabos falecios por parte de Martín Lutero en el año 1543, en claro contraste y oposición con el mencionado epigrama de Marcial, aunque, como se verá, respetando el metro, parte del lenguaje y, especialmente, la obertura de la composición original (Springer 2003, 43):

\begin{tabular}{|l|l|}
\hline Vitam quae faciunt beatiorem, & Las cosas que hacen la vida más feliz, \\
o carissime Christiane, sunt haec. & mi muy querido cristiano, son las siguientes: \\
Aeternum Dominum Deum timere, & Temer a Dios, Señor Eterno, \\
mandatique sui vias amare. & y amar los caminos de sus mandamientos. \\
Sit victus manuum labore partus, 5 & Gánate la comida con el esfuerzo de tus manos: \\
sic vivis bene, sic eris beatus. & así vivirás bien, así serás feliz. \\
Uxor prole tuam domum beabit, & Tu esposa bendecirá tu casa con hijos, \\
laetis ut generosa vitis uvis. & como la vid fecunda con gozosas uvas. \\
Ad mensam tibi filii sedebunt, & Tus hijos se sentarán en tu mesa, \\
ut pinguis tenerae novella olivae. 10 & como pingües renuevos de tierno olivo. \\
Sic fidus benedicitur maritus & Así el fiel marido es bendecido, \\
in casto domini timore vivens. & si vive en el casto temor de Dios. \\
Donet te benedictione semper & El Señor te bendiga siempre \\
ex Zion Dominus Jerusalemque & desde Sión y haga que Jerusalén \\
florentem faciat bonis vigere, 15 & esté fuerte y floreciente de bienes, \\
ut natos videas et inde natos & para que puedas ver a tus hijos y a los hijos de \\
et pacem super Israel per aevum. & tus hijos \\
Hic dicat pius omnis Amen. Amen & y la paz sobre Israel por siempre. \\
(Lutero 1559, h4r). & Que todo hombre piadoso diga Amén a esto. \\
& Amén. \\
\hline
\end{tabular}

Se trata, según se desprende de su lectura, del comienzo del epigrama de Marcial, del que tan sólo se han tomado y adaptado los dos primeros versos, mientras que el resto del poema es una versión poética, en los mismos endecasílabos usados por el poeta latino, del Salmo 128 (127), que trata sobre la felicidad de los justos y comienza, en la versión hecha desde el hebreo por Santos Pagnini, Beatus omnis qui timet dominum, qui ambulat in viis eius (Pagnini 1542, 128v). Y es que la interpretatio poética que Lutero hace del salmo en cuestión y el epigrama de Marcial presentan algunas similitudes que Lutero aprovecha para componer su versión, semejanzas como su corta extensión, sus descripciones poéticas de la vida del justo, su lenguaje sencillo para bosquejar escenas sencillas de la vida cotidiana, una sencillez que es precisamente la que reporta felicidad dentro 
de ámbito doméstico, con placeres frugales como el comer el sencillo alimento que te procure el sudor de tu frente y el disfrute de la esposa e hijos sentados todos en torno a la mesa. En cambio, las diferencias son más significativas, pues Lutero evita nombrar todos los placeres de raigambre epicúrea citados por Marcial y se centra justamente en la importancia de la familia cristiana y en los bienes que le siguen de la piedad religiosa y del amor al trabajo, aspectos éstos que el poeta romano había descartado (Springer 2007, 39). Así, Lutero saca rendimiento al precepto bíblico de ganarse el pan con el sudor de la frente (Gen. 3.19) frente a la propuesta de Marcial de disfrutar de los bienes heredados y no ganados con esfuerzo, y pone también el énfasis en la importancia del padre de familia, que ha de ser para los suyos espejo de religiosidad, piedad y observancia, y en el bienestar que aportan a la familia una buena esposa y unos hijos honrados. Son, según Lutero, estos dos aspectos, el trabajo (5-6) y la familia (7-12), junto con el temor de Dios y la observancia de los mandamientos (3-4), las virtudes morales y religiosas en las que el auténtico cristiano debe poner su mayor cuidado, para que Dios bendiga a pius omnis y le conceda la paz y la vida eterna (13-18). Marcial, en cambio, como pagano y epicúreo, había obviado el tema del matrimonio y de la familia, por ser uno de los mayores focos de perturbaciones y un impedimento para conseguir la ataraxía.

La segunda versión que Lutero compone del epigrama 10.47 de Marcial es más hiriente y sangrante. De hecho, la denomina sarcasmus, «burla mordaz y cáustica», y la dirige concretamente in Epicurum, «contra Epicuro». Está, en realidad, identificando, por antonomasia, a Marcial (y, en general, a todo hombre impío y lujurioso) con Epicuro, como si fueran una sola y misma persona. Y, de este modo, compone en el mismo metro (endecasílabos falecios) un epigrama en el que va indicando, no de forma positiva, sino por negación, todo lo que hay que hacer para ser un buen epicúreo y, en contraste, un mal cristiano:

\begin{tabular}{|l|l|}
\hline Sarcasmus in Epicurum & Sarcasmo contra Epicuro \\
Vitam quae faciunt suis beatam & Epicuro enseña que los placeres que hacen feliz \\
porcis, haec Epicurus ille tradit: & La vida a sus puercos son los siguientes: \\
ne spectes hominum Deive mentem; & No fijarse en la mente de los hombres ni de Dios. \\
non est, qui regat atque curet orbem; & Inexistencia del que gobierna y cuida del mundo. \\
spem vitae bene rideas futurae, 5 & Burlarse de la esperanza de una vida futura, \\
quamvis mens ratioque sana monstrent; & aunque la mente y la sana razón demuestran su \\
te soli tibi finge procreatum, & existencia. \\
certus cuncta tuo esse nata ventri; & Imaginarse que has sido procreado para tu \\
Silenus placeat nihilque malis; & propio provecho, \\
vivas ut tua sus tuusque porcus 10 & seguro de que todo ha nacido para tu vientre. \\
et tandem moriare porcus et sus. & Complacerte con Sileno y no preferir nada antes \\
Sic, sic itur ad insulas beatas, & que el vino. \\
aeterno quibus igne carcer ardet & Vivir como tu cerda y tu puerco \\
et tales coquit ustulatque porcos. & y, en fin, morir como un puerco y una cerda. \\
Tunc malles, Epicure, non fuisse, 15 & Así, así es como se llega a las Islas Afortunadas, \\
sed sero venient eae querelae; & en las que una cárcel arde con fuego eterno \\
et disces aliud fuisse quiddam, & Y cocina y asa a tales puercos. \\
quam quod riseris hic inane numen. & Entonces, Epicuro, preferirías no haber existido, \\
(Lutero 1559, h5r). & pero tarde vendrán ya tus quejas; \\
& y aprenderás que hay algo distinto \\
& a aquello de lo que aquí te has burlado como \\
divinidad inútil.
\end{tabular}


El poeta neolatino, como se ve, arranca su epigrama (1-2) rememorando el comienzo de Marcial, pero ya en verso 2 se aleja de él introduciendo a Epicuro como maestro de dogmas malignos y aludiendo a la secta epicúrea con el apelativo de «puercos», en clara evocación de Horacio, cuando se definió seguidor del filósofos de Samos y se autodenominó «un puerco de la piara de Epicuro»: Me pinguem et nitidum bene curata cute vises, /cum ridere voles, Epicuri de grege porcum (Epist.1.4.15-16: «Cuando quieras reír, ven a verme, pues estoy gordo y cebado y tengo la piel bien cuidada, como puerco que soy de la piara de Epicuro»). A partir de este momento, Lutero va exponiendo la doctrina a seguir si queremos condenarnos: la negación de Dios y de la providencia (3-4); la negación de la vida tras la muerte (5-6); la felicidad terrenal entendida como hedonismo y disfrutada como los cerdos (7-11); cifrar la meta del cristiano, no en la subida al cielo, sino en arribar a las Islas Afortunadas, auténtico infierno, donde entonces Epicuro pronunciará tardíos lamentos y por fin comprenderá que Dios no es esa divinidad de cuya inutilidad se ha burlado.

Lutero, evidentemente, tiene bastante dominio del latín y de la literatura clásica, aunque ciertamente no tanta soltura como, por ejemplo, Erasmo y Melanchton. Y, aunque sus textos latinos más valorados están escritos en prosa, apreciamos que sabía imitar en verso a los poetas latinos clásicos, como en estos dos epigramas citados, los cuales parten de la misma composición moral de Marcial (10.47) para derivar, mediante un claro proceso de aemulatio, en poemas religiosos y reformistas. $\mathrm{Y}$ es que parece que, siendo como era su modelo preferido Virgilio, un poeta como Marcial, perteneciente a la Edad de Plata de la Literatura Latina, le desagradaba especialmente por las altas dosis de erotismo, sexualidad y escatología que se perciben en algunas de sus composiciones y, en estos dos casos concretos, por sus apreciaciones éticas paganas y epicúreas basadas en un hedonismo que Lutero detestaba, especialmente desde que en 1525 transgredió los votos monásticos y se casó con Catalina de Bora, hecho por lo que fue acusado de epicúreo y hedonista (Springer 2007, 40). Pero Lutero, como decimos, amaba la poesía latina y la cultivó no sólo para deleitar a sus amigos cultos, como Justus Jonas y Georg Spalatin, sino también para atacar a sus opositores, como Erasmo o el papa, y para sus paráfrasis y enarrationes de la Escritura, un método apologético, el de acudir al verso de factura clásica para explicar los textos sagrados, muy antiguo y empleado por los primeros poetas cristianos. La poesía, por tanto, la entiende Lutero como un medio didáctico para atacar el epicureísmo y predicar el sano evangelio. Parece, pues, claro que cualquier lector medianamente culto identificaría en estos dos epigramas de Lutero su antecedente pagano (Marcial) y detectaría rápidamente, por comparación contrastiva, las semejanzas y diferencias entre la visión romana y pagana de la felicidad y la concepción bíblica y cristiana, decantándose, finalmente, por la felicidad que promete y ofrece la biblia y el cristianismo (Springer 2007, 35-36).

Pero hubo más recreaciones de este epigrama 10.47 de Marcial dentro de los ambientes reformistas. Johann Stigel (1515-1562), eminente poeta perteneciente al círculo humanístico melanchtoniano de Wittenberg y luego profesor en Jena, publicó también un poema luterano inspirado en los versos del poeta romano, otra aemulatio en la que, partiendo del arranque del modelo latino, se utilizan y modifican sus dos primeros versos para transformar luego la composición en una auténtica invectiva satírica contra Marcial. De hecho, el poema, dentro de su Libro de Epigramas dedicados a Ana, reina de Inglaterra, lo titula Stigel In Martialem: 


\begin{tabular}{|l|l|}
\hline Vitam quae faciunt beatiorem, & Las cosas que hacen más feliz la vida, \\
nugacissime Martialis, haec sunt: & mi muy frívolo Marcial, son las siguientes: \\
Peccati agnitio pavorque cordis, & reconocimiento del pecado y corazón \\
erroris dolor, alta poenitudo, & temeroso, \\
sola et salvificae fides salutis. 5 & dolor por las faltas, profundo arrepentimiento, \\
Nam quicumque fide mutante nusquam & y sola fe en la salvación salvífica. \\
adprendit penitus, quod ipse CHRISTUS & Pues todo el que, sin cambiar nunca su fe, \\
humanam induerit Deus figuram & ha comprendido profundamente que el mismo \\
et nobis miserisque perditisque & CRISTO \\
morti supplicioque destinatis 10 & Dios tomó forma humana \\
amissam vitio labantis Adae & y a nosotros, desgraciados y perdidos, \\
aeternam reparaverit salutem, & destinados a la muerte y al suplicio, \\
ille inter meruit beatiores & nos restituyó la salvación eterna \\
heroas statui fruique coelo. & perdida por el pecado de la caída de Adán, \\
Sunt haec barbara verba, forsan inquis,, 15 & ése mereció figurar entre los más felices \\
nec sic sunt soliti loqui Quirites. & héroes y disfrutar del cielo. \\
Vitam quae faciunt beatiorem, & Son éstas palabras bárbaras, podrás decir, \\
nugacissime Martialis, haec sunt. & y no suelen así hablar los ciudadanos romanos. \\
(Stigel 1540, c4v). & Las cosas que hacen más feliz la vida, \\
& mi muy frívolo Marcial, son éstas. \\
\hline
\end{tabular}

Stingel imita a Marcial en los dos primeros versos (1-2), que se repiten en Ringkomposition al final (17-18), cambiando el iocundissime Martialis del original por un explícito nugacissime Martialis. Y luego va exponiendo de forma positiva, claramente estructurados, los requisitos necesarios para alcanzar la felicidad cristiana: el sentimiento del pecado, del temor de Dios, del dolor por las faltas, del arrepentimiento y de la fe, la sola fides, subrayando así su credo poético luterano (3-5); la certeza de que sólo disfrutará de la gloria celestial aquel que comprenda y acepte que Cristo se hizo hombre para salvarnos (6-13); y, por último, introduciendo un interlocutor ficticio, parodiando quizás el género de la diatriba cínico-estoica cultivado, entre otros, por Horacio y Séneca, concluye con la idea de que está empleando palabras cristianas y, por ello, nuevas y desconocidas para los romanos paganos (14-15).

Otro humanista que emula el epigrama 10.47 de Marcial es Adam Siber (15161584), discípulo de Lutero y de Melanchton, pero también de otros eruditos como Justus Jonas, Johannes Bugenhagen y Caspar Cruciger, llegando a ser rector de la Escuela de San Agustín en Grimma. Encontramos, en efecto, en sus Poemas sacros la evocación del epigrama 10.47 de Marcial materializada en el desarrollo poético, en dísticos elegiacos, de uno de sus versos. Concretamente, Siber parte del verso 12 de Marcial: Quod sis, esse velis, donde se expresa la doctrina epicúrea de la autárkeia o autosuficiencia y conformidad con lo mucho o poco que uno sea y posea, pero Siber orienta su epigrama a otra clase de autarquía, ahora sagrada, consistente en la complacencia y conformidad con lo que Dios nos ha ordenado ser y tener, que es la auténtica autárkeia cristiana:

\begin{tabular}{|l|l|}
\hline Quod sis, esse velis. & Lo que seas, querer serlo. \\
Quid maiora tua fortuna concipis, atque & ¿Por qué concibes esperanzas mayores que \\
fers aegre sortis tristia fata tuae? & tu fortuna y \\
Ille sapit, laetus quisquis praesentia carpit: & llevas a mal los tristes destinos de su suerte? \\
esse velis, quem te iusserit esse Deus (Siber & $\begin{array}{l}\text { Sabio es todo el que alegre goza de lo } \\
\text { presente: }\end{array}$ \\
& Has de querer ser el que Dios te mandó ser. \\
\hline
\end{tabular}


Se percibe, como podrá notar el lector, una influencia directa del epigrama de Marcial (10.47.12) y, especialmente, del tópico horaciano del carpe diem (Hor. Carm.1.11.9), con el empleo del sintagma praesentia carpit (3), pero es ya un carpe diem cristianizado, pues este «goza del presente» no es más que la complacencia y conformidad con lo que de bueno o de malo Dios nos ha enviado.

Por su parte, Nicolás Reusner (1545-1602), que estudió en Wittenberg y ejerció su docencia en Estrasburgo y en Jena, vuelve a imitar el epigrama de Marcial en clave cristiana en el libro primero de sus Odas sacras, dirigidas Ad Iesum Christum, en un epigrama dedicado «al cristiano príncipe de Noruega», Cristián IV, el hijo de Federico II de Dinamarca, una composición que, partiendo del conocido modelo latino, va destinada al puro y sereno Cristiano (Cristián IV, que también es un perfecto cristiano) y se convierte en una paráfrasis de los Diez Mandamientos, que han de ser los que guíen provechosamente a Cristián IV como decálogo de la vida feliz y cristiana dentro de la teología luterana:

\begin{tabular}{|l|l|}
\hline Vitam quae faciunt beatiorem, & Las cosas que hacen más feliz la vida, \\
serenissime Christiane, sunt haec: & serenísimo Cristiano, son las siguientes: \\
cultus numinis unici Iehovae; & el culto de Jehová, el único Dios, \\
iuris cautio magna peierati; & gran cautela con el perjurio, \\
sacrorum pia sanctitas dierum; 5 & piadosa santidad de los días sagrados, \\
sancto debita caritas parenti; & el amor debido al Santo Padre, \\
pura mens odii manusque caedis; & mente exenta de odio y mano limpia de crímenes, \\
lecti sobria castitas iugalis; & sobria castidad del lecho conyugal, \\
iuris sanctus honos et aequitatis; & santo respeto al derecho y la equidad, \\
fides integra veritasque nuda; 10 & fe íntegra y verdad desnuda, \\
abstinentia proximi bonorum, & abstenerse de los bienes del prójimo: \\
servi, coniugis, aedium boumque. & de su esclavo, esposa, casa y bueyes. \\
summa haec est: homines ama Deumque & Lo esencial es esto: ama a los hombres y a Dios \\
toto corde animoque, mente tota, & con todo tu corazón y espíritu, con toda tu mente, \\
vitam vivere si beatiorem 15 & si deseas vivir una vida más feliz \\
per Christi meritum cupis beatus & siguiendo felizmente los méritos de Cristo. \\
(Reusner 1593, 126) & \\
\hline
\end{tabular}

Se trata, en efecto, de los mandamientos recogidos en el Catecismo menor de Lutero, pero revestidos didácticamente de ropaje poético para su mejor asimilación por el príncipe cristiano Cristián: 1) No tendrás dioses ajenos delante de mí $(3) ; 2)$ No tomarás el nombre de Jehová tu Dios en vano (4); 3 ) Acuérdate del día de reposo para santificarlo (5); 4) Honra a tu padre y a tu madre, para que tus días se alarguen en la tierra que Jehová tu Dios te da (6); 5) No matarás (7); 6) No cometerás adulterio $(8)$; 7) No hurtarás $(9)$; 8) No hablarás contra tu prójimo falso testimonio $(10)$; 9) No codiciarás la casa de tu prójimo; y 10) No codiciarás la mujer de tu prójimo (11-12). Y termina el epigrama con la summa de la doctrina cristiana: el amor al prójimo y a Dios, imitando la conducta virtuosa de Cristo, es lo que nos concede la felicidad en esta vida y la salvación en la vida celestial (13-17).

En otra oda que sigue inmediatamente a la anterior, dirigida ahora al príncipe Felipe de Noruega (1570-1590), duque de Holstein e hijo de Adolfo de Dinamarca o Adolfo de Holstein-Gottorp (1526-1586), Reusner vuelve a inspirarse en Lutero $\mathrm{y}$, así como éste centró una de sus adaptaciones de Marcial en el tema de la vida futura y eterna después de la vida terrenal y expuso, por negación, las doctrinas epicúreas que llevarían al cristiano a la condenación eterna, ahora el humanista de 
Löwenberg toma también la vida futura tras la muerte como punto de partida para su poema (Springer 2007, 48) e, igual que Lutero, expone por vía negativa todo lo que el cristiano debe hacer si, en vez de salvarse, lo que quiere es condenarse. Reusner, como podrá leerse, reelabora su anterior epigrama y vuelve a exponer, mediante la oposición y la contrariedad, los mandamientos luteranos, dictando, no las conductas que deben seguirse y que nos harán feliz, sino, al contrario, las acciones que deben evitarse porque nos harán desgraciados y pecadores:

\begin{tabular}{|l|l|}
\hline Felicem minus et minus beatam & Las cosas, Felipe, que hacen la vida \\
vitam quae faciunt, Philippe, sunt haec: & menos feliz y menos dichosa son las siguientes: \\
cultus semihominum impius deorum; & el culto impío a dioses semihombres, \\
iuris cautio nulla peierati; & ninguna cautela con el perjurio, \\
profanatio Sabbathi nefanda; 5 & la profanación criminal del Sabbat, \\
sanctorum violatio parentum; & la violación de los sagrados padres, \\
caedes atque manus nefas cruentae; & la matanzas y sacrilegios de una mano cruenta, \\
stupri adulteriique foeda labes; & la vergonzosa mancha del estupro y del \\
prompta fallere mens manusque furax; & adulterio, \\
et mendacia vanitasque linguae; 10 & una mente pronta a engañar y una mano \\
cupido mala proximi bonorum, & ladrona, \\
servi, coniugis, aedium boumque. & y una lengua mendaz y vanidosa, \\
Si quis haec habet, haud erit beatus & la codicia mala de los bienes del prójimo: \\
(Reusner 1593, 127). & de su criado, esposa, casa y bueyes. \\
& Si alguien tiene todo esto, no será feliz. \\
\hline
\end{tabular}

En los mismos círculos luteranos y reformistas que los autores estudiados encontramos también a Matthias Berg (1536-1592), rector de la Escuela en Bruswick, quien publicó en 1573 dos libros de Poemas evangélicos, en los que quiso incluir, siguiendo a los poetas luteranos, su propia adaptación del epigrama 10.47 de Marcial. Quería sumarse así a esa tradición de cristianizar la poesía pagana y emplear el verso neolatino de tono religioso para fines didácticos y evangelizadores (Deufert 2011, 75-82), dirigiéndose, no obstante, en vocativo a la sabiduría y la poesía, personificadas mediante prosopopeya, y no ya a Marcial ni a Epicuro ni a ningún cristiano concreto. Se trata de echar en cara a ambas destinatarias que la gloria que procuran la sabiduría y la poesía, gloria vana, no tiene nada que ver con la auténtica felicidad que alcanza quien sigue los dictados evangélicos:

\begin{tabular}{|l|l|}
\hline Vitam quae faciunt beatiorem, & Las cosas que hacen más feliz la vida, \\
o nugax Sophia et poesis, haec sunt: & ¡sabiduría y poesía frívolas!, son las siguientes: \\
CHRISTO non dubia fide prehenso & abrazar a Cristo con fe firme \\
damnantis veniam invenire culpae, & y encontrar el perdón del pecado que nos \\
Supremi Patris ex benignitate, 5 & condena, \\
ob Gnati meritum, nec illa mentis & conforme a la bondad del Padre Supremo, \\
vana haurire ab imaginatione, & por los méritos del Hijo, y no sacar ideas vanas \\
sed verbi quasi pastibus cibatum, & de la imaginación de la mente, \\
sanctis pastibus, inde ducere omnem & sino, cebados, por así decir, con el pasto de la \\
Dei noticiam suique Christique, 10 & palabra, \\
inde est iusticia, inde vera mentis & los sagrados pastos, obtener de ahí todo \\
pax et gaudia sine clausa nullo. & el conocimiento de Dios, de sí y de Cristo, \\
Hinc qua te statione collocavit & origen de la justicia, origen de la verdadera paz \\
Rectoris bona coelici voluntas, & espiritual y de los gozos sin límite. \\
dati muneris ire per labores, 15 & Y en la residencia en la que te ha colocado \\
& la buena voluntad del regidor del cielo, \\
\hline
\end{tabular}




\begin{tabular}{|c|c|}
\hline rre; 20 & $\begin{array}{l}\text { ar por las fatigas del don concedido } \\
\text { r a Dios el término del tiempo futuro } \\
\text { ente, y lo que él } \\
\text { diga, sea tristeza o alegría, } \\
\text { enviado desde la diestra del mejor padre, } \\
\text { rlo con bendición, } \\
\text { umirte miserablemente en la preocupación } \\
\text { l tenaz cieno de las cuitas. } \\
\text { el que vive la vida según estos preceptos, } \\
\text { provechoso a los demás, a sí mismo y a los } \\
\text { coge para sí la parte } \\
\text { inca desaparece. Tal suerte hay que buscar. }\end{array}$ \\
\hline
\end{tabular}

El epigrama, de nuevo dispuesto en composición anular, pues lo abre y cierra el mismo endecasílabo, es el más largo de los estudiados hasta ahora y también el que más se distancia tanto de la fuente clásica como de Lutero. Evocando el comienzo del Eclesiastés, parece que Berg quiere proclamar que todo en la vida terrena es vanidad, pero especialmente la sabiduría humana, porque tanto el sabio como el necio morirán (Ecc. 2.15-16). En cambio, hay otra vida, la vida del cristiano, que, basada en la fe (verso 3), en la búsqueda del perdón del pecado (4) por la bondad de Dios y del Hijo (5-6), ha de encontrarse en la única fuente del saber que debe proponerse el piadoso para conocerse a sí mismo y también a Dios y Cristo, los Evangelios, esto es, el manantial de donde brotan los placeres, no mundanos ni hedonistas, sino divinos y salvíficos (6-12). Y así, Matías Berg contrasta la vida terrena presente, que ha de ser una vida de fatigas para el hombre por el don concedido por Dios, con la vida futura que vendrá tras la muerte, en la idea de que la resignación, serena, gozosa y sin lamentos, con lo dispuesto por Dios en la vida terrena nos encumbrará a la vida feliz que nos espera en el cielo (13-22). Sólo quien viva siguiendo estos sanos preceptos evangélicos, concluye Berg, tendrá en la tierra una existencia provechosa para sí y para los demás hombres, pues habrá escogido, no la parte humana corporal, sino la espiritual, la que nunca fenece y la que nos da acceso a Dios y a la vida futura (23-26).

\section{Marcial redivivo}

El escritor holandés Peter Schrijver o Schryver (1576-1660), conocido con su nombre latinizado como Petrus Scriverius, formado en la Universidad de Leiden y luego director de la Escuela Latina en Duisburg (Alemania) entre 1611-1613, fue amigo y defensor de Hugo Grocio (1583-1645), a quien dirigió una serie de poemas para apoyarle en sus debates religiosos contra los gomaristas, lo que le costó una importante multa. Se granjeó Scriverio una buena fama entre los humanistas contemporáneos por sus contribuciones filológicas, editando y comentando la obra de Ausonio, el Pervigilium Veneris, los poemas latinos de José Justo Escalígero (Leiden 1615), el tratado militar de Vegecio o las Tragedias de Séneca. Pero aquí nos interesa por sus aportaciones a la obra de Marcial, cuya obra sometió a unos comentarios críticos en su libro Animadversiones in Martialem (Leiden 1618); y también la editó con mucho éxito bajo el título M. Val. Martialis nova editio, ex museo Petri Scriverii (Leiden 1619), conociendo después esta edición numero- 
sas reediciones (Botley 2016, 95-108). Nos interesa, pues, su edición de Marcial porque al comienzo de la misma encontramos dos poemas latinos, escritos por su amigo Hugo Grocio, que van destinados a alabar la persona de Scriverio y su mencionada edición. En uno de ellos, en efecto, nos presenta a Scriverio como el auténtico resucitador de Marcial por haber dado a la luz una nueva edición de sus epigramas. Y lo hace Grocio, como ya viene siendo habitual, componiendo un epigrama en el mismo metro que el vate romano y que toma por modelo el primer verso del poema 10.47 de Marcial, repetido en la obertura y en la clausura para conformar así una Ringkomposition:

\begin{tabular}{|l|l|}
\hline Vitam quae faciant beatiorem, & Lo que hace la vida más feliz lo muestra \\
cantando tuus ille Martialis, & con sus versos tu querido Marcial, \\
tu multo melius doces agendo, & pero tú lo enseñas mucho mejor con tu obra, \\
Scriveri, redivive Martialis. & Scriverio, Marcial redivivo. \\
Quicquid Graecia, Roma quidquid olim 5 & Todo lo que Grecia, lo que antiguamente Roma \\
fama condidit arbitra probatum & edificaron y la fama espectadora aprobó, \\
uno compositum tenere tecto; & tenerlo reunido bajo un mismo techo; \\
nulli pendere temporis tributum, & no estimar en nada el tributo del tiempo, \\
sed pro iure suo diebus uti & sino disfrutar por propio derecho de los días \\
ignaris domini, nec elocatis; 10 & que no conocen dueño ni arrendatario; \\
si quando libuit vetusta vatum & si alguna vez agradó evocar los antiguos \\
dulci saecula provocare versu, & siglos de los vates con dulce verso, \\
aut priscos Patriae novare Fastos, & o renovar los viejos Fastos de la patria, \\
norit posteritas ut omnis, auctu & para que toda la posteridad sepa cuán crecida \\
quo se protulerit Batava virtus, 15 & se presentó la virtud bátava, \\
quae secura sui, nihil pavescens, & que, segura de sí y sin temor alguno, \\
iam longe positos tuetur Indos; & ya protege a los remotos Indos, \\
aut doctas veterum polire chartas, & o pulir los doctos pergaminos de los antiguos, \\
quas Mars, quas sibi Terminus sacravit; & que Marte y que Término consagraron para sí; \\
et votis sitientibus petitum, 20 & y tras buscarlo con sedientos deseos, \\
qualem Stella legebat, aut Secundus, \\
talem nunc redhibere Martialem; \\
haec sunt (audiat ipse Martialis) \\
vitam quae faciunt beatiorem. \\
devolvernos a Marcial ahora tal \\
como lo leían Estela o Segundo; \\
todo esto (que lo oiga bien Marcial) \\
es lo que hace la vida más feliz.
\end{tabular}

Grocio, como se ve, eludiendo toda referencia religiosa, reformista y protestante, tiene en gran estima a Marcial como poeta y en especial pondera la importancia de leerlo por la edición que ha realizado Scriverio. De este modo, elogia al poeta romano por enseñarnos con sus versos su ideal epicúreo de felicidad, pero más aún a Scriverio, a quien califica como un nuevo Marcial, por haber confeccionado las dos obras antes mencionadas, esto es, unos comentarios críticos y, en fin, una depurada edición del texto latino (1-4). La trascendencia de la edición de Scriverio radica en que todo el saber griego y romano contenido en el poemario de Marcial por fin está reunido en un solo volumen (5-7), que nos hará disfrutar de nuestro ocio leyéndolo (8-10); además este volumen editado por Scriverio servirá también para conocer la grandeza de la antigua Roma, comparable ahora a la nueva grandeza de los Países Bajos, que ya en 1608 habían fundado su primera colonia en la India (10-19); pero, en suma, el mayor mérito de Scriverio, y quiere Grocio que el propio Marcial lo escuche perfectamente, es haber buscado fervientemente 
los manuscritos de Marcial y habernos ofrecido en su edición el texto original y auténtico que escribió el poeta romano y que en sus días leyeron Estela o Segundo, ambos amigos de Marcial.

\section{Conclusiones}

En el presente trabajo se ha puesto de manifiesto una de las premisas de las que partía la investigación, a saber, que el epigrama 10.47 de Marcial es posiblemente el más famoso de toda su colección a tenor de las múltiples imitaciones y recreaciones que ha tenido a lo largo de su tradición clásica.

Concretamente, hemos ahondado, no tanto en las versiones e imitationes literarias que dicho epigrama ha tenido en la historia literaria de Occidente (un tema, por lo demás, abordado ya por otros estudiosos), como en las aemulationes que ha conocido el poema en el mundo cristiano. Hemos puesto, efectivamente, de manifiesto que la mencionada composición de Marcial, sin duda teñida de epicureísmo, es objeto en numerosas ocasiones de una cristianización que toma como punto de partida el Neoepicureísmo y el Neoestoicismo que tanta fortuna tuvieron en el Humanismo del Renacimiento. Y esta cristianización de Marcial, no sólo se practica en el ámbito del catolicismo cristiano, como es el caso de la imitación practicada por Juan de Silva, Conde de Portalegre, sino especialmente en los círculos cristianos luteranos, protestantes y reformistas, que aprovechan los versos de Marcial para, dejando constancia de que parten del poeta romano, alterar la intentio auctoris del original y convertir sus endecasílabos paganos y epicúreos en endecasílabos cristianos y catequísticos de sabor luterano. En este sentido, estos epigramas escritos a imitación del de Marcial por Lutero, Stigel, Siber, Reusner o Berg se convierten en poesía dogmática y didáctica de cariz luterano y, al mismo tiempo, en un manifiesto claramente antiepicúreo y, por extensión, antimarcial, aunque es evidente que los versos de Marcial los conocen y los aprecian. Parece, pues, que, siguiendo idéntico método didáctico que sus odiados poetas epicúreos, estos poetas neolatinos han recurrido al mismo artificio sutil e ingenioso que empleó Lucrecio, esto es, han expuesto la verdad de su doctrina reformista con el ropaje del verso y la han untado con la dulce miel de la poesía, por ver si así cautivaban los ánimos del lector y lo convencían de la utilidad de esta doctrina luterana, del mismo modo que el médico avezado unta de miel los bordes del vaso que contiene la amarga medicina (cf. Lucr. 4.11-25). Estos poetas neolatinos se sienten médicos del alma y con el dulzor de la poesía, inspirada formalmente en Marcial, pero con otras derivaciones e intenciones, pretenden insuflarnos la veracidad y provecho de sus doctrinas religiosas.

Otro caso diferente es el del humanista Hugo Grocio y su imitación del epigrama 10.47 de Marcial. No busca su autor más que ensalzar los trabajos filológicos de Scriverio, que con grandes esfuerzos ha centrado sus meritorias investigaciones en la crítica y edición de la poesía del mencionado vate romano.

Todas estas composiciones, en fin, muestran que este epigrama de Marcial quizás sea el más famoso de su colección y que lo mismo da juego para realizar sobre su base un ejercicio retórico de versio o imitatio como para acudir directamente a la recreación poética (aemulatio) con intenciones didácticas o epidícticas. Todos estos poemas neolatinos son, sin duda, excelentes ejercicios retóricos del género demostrativo, dirigidos bien a la censura del epicureísmo, según vemos en Lutero, Stigel, Siber, Reusner o Berg, bien al elogio, como en el caso de Grocio, de Marcial y de Scriverio, un redivivus Martialis. 


\section{Bibliografía}

\section{Fuentes}

Berg, M. (1573), Carminum Evangelicorum libri duo, Henricopoli excudebat C. Horn.

Korreas, G. (1630), Ortografia Kastellana... El Manual de Epikteto i la Tabla de Kebes, filósofos estoikos... traduzidos de Griego en Kastellano por el Maestro Gonzalo Korrea, Salamanka, X. Tabernier.

Lutero, M. (1559), In Psalmos vigintiquinque priores et sequentes aliquot enarrationes, Noribergae, I. Montanus \& V. Neuberus.

Marcial $(1987=1903)$, M. V. Martialis Epigrammata, ed. Lindsay, W.M., Oxford, Oxford University Press.

Pagnini, S. (1542), Biblia sacra ex Sanctis Pagnini traslatione, Lugduni, H. a Porta.

Quevedo, F. de (1635), Defensa de Epicuro contra la común opinión, ed. Acosta Méndez, E. (1986), Francisco de Quevedo. Defensa de Epicuro contra la común opinión, Madrid, Tecnos.

Reusner, N. (1593), Operum N. Reusneri ... Pars secunda, Ienae, T. Steinmannus.

Rosal, F. del; Thompson, B.B. (1975), Dr. Francisco del Rosal... La razón de algunos refranes, Londres, Tamesis Books Limited.

Sánchez de las Brozas, F. (1612), Dotrina del Estoico Filósofo Epicteto, que se llama comúnmente Enchiridion, Barcelona, Erederos de Onofre Anglada.

Scrivonio, P. (1618), Animadversiones in Martialem, Lugduni Batavorum, I. Maire.

Scrivonio, P. (1619), M. Val. Martialis nova editio, ex museo Petri Scriverii, Lugduni Batavorum, I. Maire.

Siber, A. (1566), Poematum sacrorum pars prima, Basileae, Oporinus.

Stigel, I. (1540), Ad Henricum Octavum Angliae et Franciae Regem Carmen Elegiacon. Item Gratulatoria adhortatio, Ioanne Stigelio Autore. Ad Gulielmum Ducem Iuliae... Ad Annam Ducem Iuliacensem liber epigrammaton, s. 1.

\section{Estudios}

Bouza, F. (1994): «Corte es decepción. Don Juan de Silva, Conde de Portalegre», en Martínez Millán, J. (dir.), La corte de Felipe II, Madrid, Alianza Editorial, 459-462.

Botley, P. (2016), Richard 'Dutch' Thomson, c. 1569-1613. The Life and Letters of a Renaissance Scholar, Leiden-Boston, Brill.

Cristóbal López, V. (1987), «Marcial en la literatura española», en Actas del Simposio sobre Marco Valerio Marcial, Ponencias, Zaragoza, UNED, 145-210.

Damschen, G.- Heil, A. (2004), Marcus Valerius Martialis. Epigrammaton liber decimus. Das zehnte Epigrammbuch. Text, Übersetzung, Interpretationen. Mit einer Einleitung, Martial-Bibliographie und einem rezeptionsgeschichtlichen Anhang, Francfort del Meno, Peter Lang.

Deufert, D. (2011), Matthias Bergius (1536-1592). Antike Dichtungstradition im konfessionellen Zeitalter, Göttingen, Vandenhoeck \& Ruprecht.

Encuentra Ortega, A. (2015), «De la vida más feliz a la vida eterna: Marcial 10.47 y las orationes de Ausonio y Paulino», Revista de Estudios Latinos (RELat), 15, 53-79.

Faber, F. W. (1860), Spiritual Conferences, Londres, Th. Richardson and Son.

Gil, J. (2004), «Marcial en España», Humanitas 56, 224-326. 
Giulian, A. (1930), Martial and the epigram in Spain in the sixteenth and seventeenth centuries, Filadelfia, University of Pennsylvania.

Guillén, J. (2004), Epigramas de Marco Valerio Marcial, Zaragoza, Institución 'Fernando el Católico'.

Laguna Mariscal, G. (2000), «Cosas que procuran una vida feliz: contenido y fortuna literaria del epigrama X 47 de Marcial», en Homenaje a la profesora Carmen Pérez Romero, Cáceres, Universidad de Extremadura, 321-337.

Laguna Mariscal, G. (2017), "'Cosas que hacen que valga la pena vivir': de Marcial a Christophe Plantin», en Oñoro Otero, C. y Saz Rivera, D. M. (eds.), Recherches. Culture et Histoire dans l'Espace Roman 18 (Printemps 2017). Voces y vías múltiples, Estrasburgo, Presses Universitaires de Strasbourg, 55-71.

Leberl, J. (2004), Domitian und die Dichter, Göttingen, Vandenhoeck \& Ruprecht.

Mañas Núñez, M. (1997), «La rehabilitación de Epicuro en el Humanismo renacentista: la Defensio Epicuri de Cosma Raimondi», en J.M. Maestre Maestre, L. Charlo Brea y J. Pascual Barea (eds.), Humanismo y pervivencia del mundo clásico: Homenaje al profesor Luis Gil, Cádiz-Alcañiz, Instituto de Estudios Turolenses, vol. I, 137146.

Menéndez Pelayo, M. (1951), Biblioteca hispano-latina clásica. Vol. VII, Madrid, CSIC.

Paladini, M. (2011), Lucrezio e l'epicureismo tra Riforma e Controriforma, Nápoles, Liguori.

Rodríguez Moñino, A. R. (1932), «El 'Avoir une maison...' de Chr. Plantin y el 'Vitam quae faciant beatiorem...' de Marcial», Revista de la Biblioteca, Archivos y Museos, año IX, $\mathrm{n}^{\circ}$ XXXVI, octubre, 439-449.

Springer, C. P. E. (2003), «Arms and the Theologian: Martin Luther's Adversus Armatum Virum Cochlaeum», International Journal of the Classical Tradition, Vol. 10, No. 1, Summer, 38-53.

Springer, C. P. E. (2007), «Martin's Martial: Reconsidering Luther's Relationship with the Classics», International Journal of the Classical Tradition, Vol. 14, No. 1/2, Summer, 23-50.

Springer, C. P. E. (2011), Luther's Aesop, Kirksville, Truman State University Press.

Sullivan, J. P. (1986): «Some Versions of Martial 10.47; the Happy Life», CO 63, 112-114.

Sullivan, J. P., (1991), Martial: the unexpected classic. A literary and historical study, Cambridge, Cambridge University Press.

Unamuno, M. de (2012), Diario íntimo, ed. E. González López, Salamanca, Ediciones Universidad de Salamanca.

Watson L. \& P. (2003), Martial. Select Epigrams, Cambridge, Cambridge University Press.

Zubizarreta, A. (1960), «Don Miguel de Unamuno, lector del P. Faber», Salmanticensis 7 , $667-701$. 